
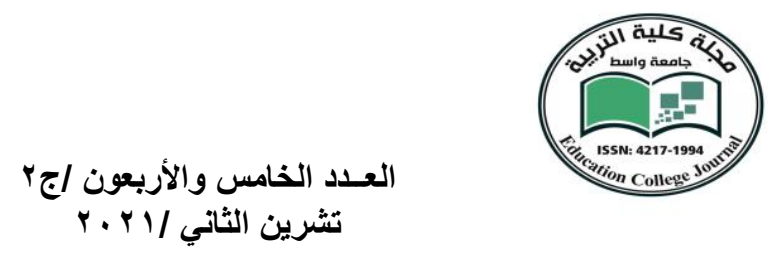

\title{
The Tragic Sense in the Theatre of the Absurd: The Case of Pinter's Birthday Party
}

\author{
Assist. Lect. Safaa Hussein Sagheer ${ }^{1}$ \\ Lect. Mehdi Abbass Mohsin ${ }^{2}$ \\ English dept. /I. K. U. C., Wasit, Iraq./ Wasit \\ safaahussein@alkadhum-col.edu.iq
}

\begin{abstract}
Absurdity is a prominent philosophy associated with the emergence of modernist and postmodernist movement in literary text. In such texts, we notice that the embedded themes and ideas reflect the dilemma and the suffering of modern man. The purpose of this paper is to attempt clarifying the subtle feeling that associates with the emersion of modernist and postmodernist movements, and discussing the ideas of absurdity and absolutism. Also, it gives an idea about the sense of sickness associates with the anomalies of the human conduct on the projected scene such as a universe of meta--identity, named the hilarious theater. This type of theatre is commonly known as absurd theater as discovered by Martin Julius Esslin (1918-2002), who created this phrase to explain that Meta identity has been substantially reinterpreted through an exterior identity mask, which invigorates one of the postmodern ideological conceptions of the enormous humanity. The paper consists of three sections: the first is an introduction to Pinter's Birthday Party. The second section discusses the concept of absurdity and the reason of its emergence. The third section deals with how absurd themes reflect the pain, the sense of loss and void that modern man experiences amid the chaotic world specifically after WWII. Finally, the study ends up with conclusion and recommendations for further studies.
\end{abstract}

Keywords: absurd, existence, tragedy, catastrophic, disillusionments, humankind. 


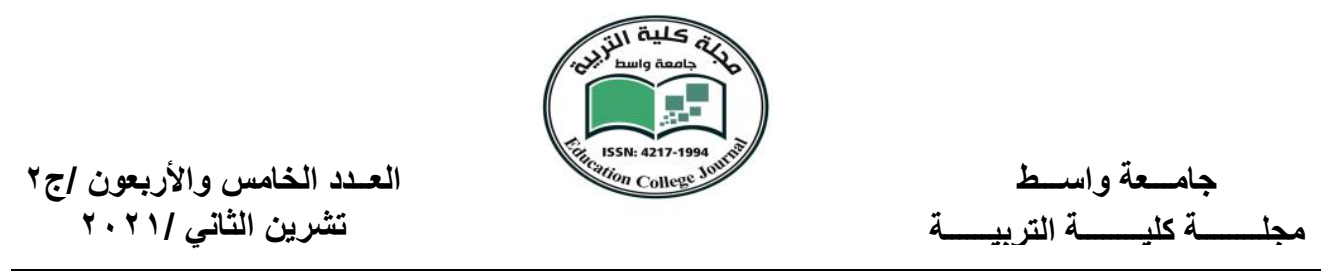

الثعور المأساوي في مسرح العبث: حالة حفلة عيد ميلاد بينتر

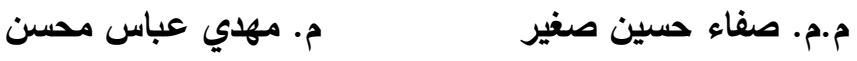

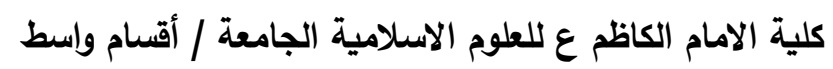

safaahussein@alkadhum-col.edu.iq

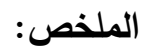

العبثية فلسفة بارزة مرتبطة بظهور الحركة الحداثية وما بعد الحداثية في النص الأدبي. في مثل هذه النصوص ، نلاحظ أن الموضوعات والأفكار المضمنة تعكس معضلة ومعاناة الإنسان الحديث.

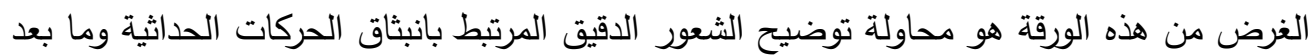

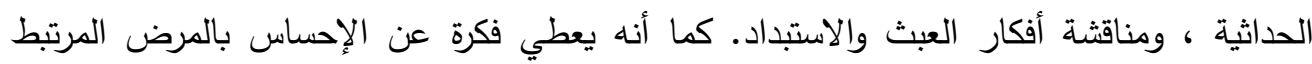

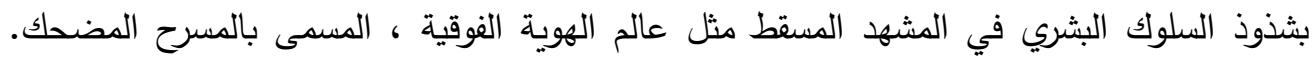

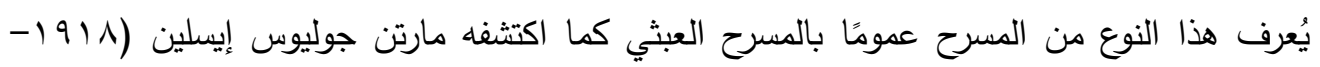

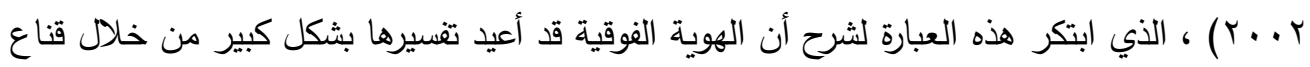

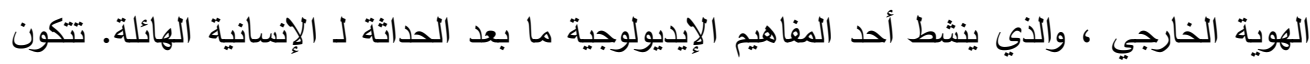
الورقة من ثلاثة أقسام: الأول هو مقدمة لحفلة عيد ميلاد بنتر ـ أما المبحث الثاني فيناقش مفهوم

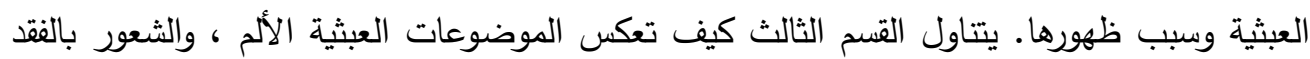
والغراغ الذي يعيثه الإنسان الحديث وسط عالم الفوضى تحديدًا بعد الحرب العالمية الثانية. أخيرًا ،

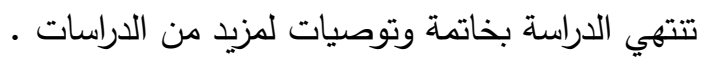




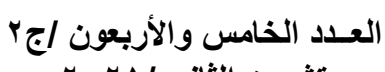

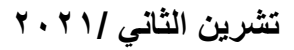

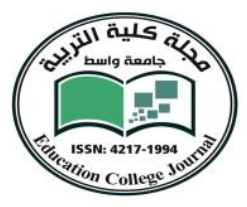

\section{Introduction}

Birthday Party is one of Harold Pinter great plays written in (1957). The title of the play might not be appropriate to the content or match with the message that the writer wants to deliver. However, in traditional sense, birthday party implies joy and happiness but in the context of the play happened horror. The main character of the play is Stanley who used to be former pianist but currently he does not practice his pianist job. That is all about the historical background of the protagonist of the play who lives in Mr. Petey and Mrs. Meg's boarding house which is seemingly a suitable place for him. Bennet (2011) elaborates that Stanley is a former pianist with no more information about his history, preferring to take Meg and Petey's boarding house as a safe accommodation. The play talks about two outsiders Goldenberg and MacCann as sources of menace, coming to the place where Stanley lives. A birthday party occurs in Meg and Petey's boarding house. However, the birthday party is shown in the play rather unpleasant and full of menace and fear instead of being full of pleasance and joy (Mohsin \& Sagheer,2019). The setting of the play reflects the circumstances of a world characterized as full of menace, void of values and meaningless. This is the way that modern man experiences. Ali \& Pourgiv (2006) theorizes that Pinter's characters show a multi- perspective way of looking at the world modern people live at. It is theorized that the characters are lost in a world that is full of contradictions rather than a world, expressing traditional reality which is reflected in the realist movement in literature. Such reality cannot fulfill their desires, however, the absurdity alludes such desires (Mohsin \& Sagheer,2019). The central theme of the play concentrates on how modern individual suffers from the lack of interest and affection which are the basic properties of human nature. The tragedy of modern man shows that modern man has lost the sense of happiness and joy expressed via love and affection which are used only to experience the past but the status quo compels $\mathrm{him} /$ her to live alone. It is observed that Meg takes care of Stanley same as her son, for instance, she goes to his room to wake him up for breakfast. Lulu is another character of the play. She would like to join Stanley for a trip or a picnic. We notice that Stanley recollects only pain and the lack of love and affection of his previous life but with no detailed information about what was 


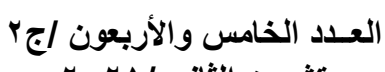

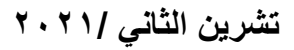

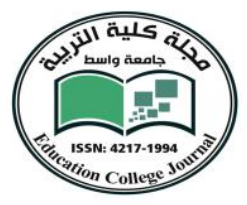

going on with him earlier in his life. Such circumstances express the tragedy of the protagonist in previous life and in current life specially when the two strangers McCann and Goldberg arrives the boarding house and join the birthday party. Moreover, Meg and Petey also suffer from the lack of interest in love and emotional orientation towards each other. The two bad outsiders McCann and Goldenberg come to this house to metaphorically to simulate the sinister forces which destroy the modern world. The atmosphere of the play exhibits a lack of communication of human qualities and expresses equivocation in all aspect of social life. This might be shown via the setting of a world which is characterized as full of tragic moments , meaninglessness and loss.

\subsection{The Emergence of Absurd Theatre and its Impact}

The Absurd Theater is not a premeditated theater movement.

The playwrights classified under this category are not part of any institute of thinking. The avant-garde thinkers convey their individual views and universal views. Notwithstanding, mostly through their new expressive modes, the audience is confronted with new norms which are to some extent similar in their firm renouncement of well-formed principles of plays. In Absurd plays, The characterization, justified acts, intelligent and rationally built-in dialogues witness a lack of ordinary sense (Gaensbauer, 1996). These matches are arbitrary and arbitrarily terminated. They had an instantaneous impact on the crowd when they appeared. In unorthodox subjects and approaches they expressed the worldview of playing wrights. They sought to attain their goals on their own, and thus they developed new frameworks that are more or less tied to cultural circumstances of dramatic expression. In approach and methodology, critics detect fundamental parallels. The spiritual atmosphere of the period, the disposition of the day, the collective custom and the universal context of creative inspirations are the source. There has been the term of the Theater of the Absurd given to the special dramatic norms that certain playwrights observe. In a setting that is certainly not derived from actual life, Eugene Ionesco's Amedee presents a middle-aged woman and husband. The woman gets her bread by controlling a kind of telephone intercom; the husband writes a piece and the bedroom has been 


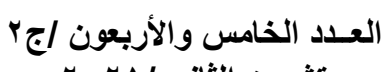

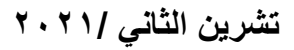

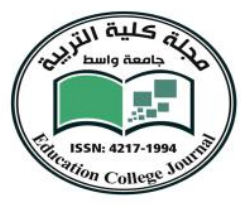

lifeless for long. It might be the corpse of the lover of a woman that the husband killed, or of a thief or of an outcast guest (Lewis, 1972). It is becoming wider and wider, and during the play, it becomes bigger and larger, such that a huge foot ultimately emerges from the bedroom in the living room and threatens to push Amedee and his wife out. All of this is terrific, yet all of these things we have dreamed about. Illogically, dreams evolve and depict pictures. They are hence vague and have a variety of interpretations. What the developing body stands for - it might suggest the increasing strength of previous errors or culpability - or the death of love or attachment to some evils that threatens the family. It is uncertain what it is.

These disillusionments tended to be absolute in the twentieth century. The confidence in religion has gone all along. At the aftermath of the World War First, the prior belief in the unavoidable societal development faded as Karl Marx's followers eventually made totalitarian, not less despotic nations than fascist ones (Caselli \& Beketts, 1997). There was a brutal strangulation of free spirit throughout the whole continent rather than peace and growth. After the World War Second, delicate intellectual scholars from all nationalities could examine even externally affluent, attractive cultures and detect only their spiritual emptiness. In the middle of this century, previous assurances evaporated. Nightmares now fill the world of sensitive artists. Many have decried Victorian pleasure, yet it offered individuals at least a nice sensation, whereas spiritual suffering only comes utter disappointment. Sir James Jeans, who spoke about the enigmatic world a long time ago, voiced one sort of disappointment for the scientists who believed that the world is unimaginable and in contrast that the life of man should not be significant for the Creator. This is a sort of sleepy vision. There is another form of complacency breakdown in the post-world war. Men realize that the ancient foundations on which their ancestors constructed their citadel of belief were disappearing. As Martin Esslin depicted it, man looks at himself suddenly as a world which, in a word, is scary and unreasonable. All hopes, promises, any ultimate meaning explanation were startling illusions revealed, empty conversations, groping in the obscurity. If we attempt to envisage such a circumstance in everyday life, it may be that we would suddenly cease to comprehend what the dialogue was in a crowded room: what was meaningful at one point becomes an 


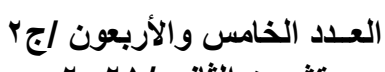

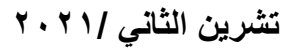

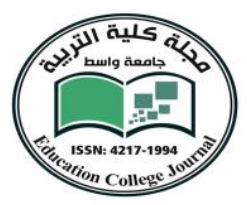

obscure vocal cacophony. At immediately, the familiar, comforting image would become one of horror and nightmares. The plays reflect to a greater extent on the ideas of existentialism of Kierkegaard, Dostoevsky, Sartre, Camus, Nietzsche and project aptly what happens while the existence of human is stripped of meaning or purpose and the total communication process breaks down.

Theater of the Absurd has significant relationships with modernism, mainly through Samuel Beckett's work, but it is a modernity that finds little or no reason for hope or optimism in the second half of the 20th century. Martin Esslin, inventor of the phrase "Theater of the Absurd" so defined it. The characteristic of [the mentality behind] is that it has been washed away from the certainty and inexhaustible basic assumptions of the past eras, tested, and found wanting, dismissed as cheap and sometimes juvenile illusions. The collapse in religious belief was hidden by progressive religions of faith, nationalism and different totalitarian illusions until the conclusion of the Second World War. The battle ruined this whole thing. In the 1942 book Myth of the Sisyphus of Albert Camus used 'absurdity' to illustrate the miserable human condition: 'This separation between the humans and their life, between the actors and their places, veritably establishes the sense of the 'Absurdity' and, in 1957, he had defined it: 'Absurd is what is purposeless. The question is how does it relate to the tragic if any? This paper critically analyses the deep rooted tragic sense in the theatre of the absurd literature.

\subsection{Literature Review}

The several pieces, now gathered together as part of the Absurd Theater, convey the playwright's dismay at the dismissal of ancient institutions and convictions. Albert Camus has presented a sense of man in The Myth of Sisyphus (1942) in a realm of fragmented faiths; a universe in which man must attempt to evade suicide since evading is no longer feasible on the wings of poetry. It is a universe, however imperfect, that cannot be explained by rationality. Here the man feels like a stranger robbed of all illusions. He is not only bereft of the world of his acquaintance but also 'deprives him of the hope of a promised country.' Berenger reflects Eugene Ionesco's mood in the 


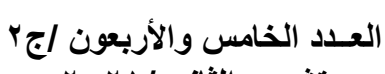

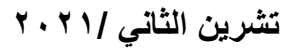
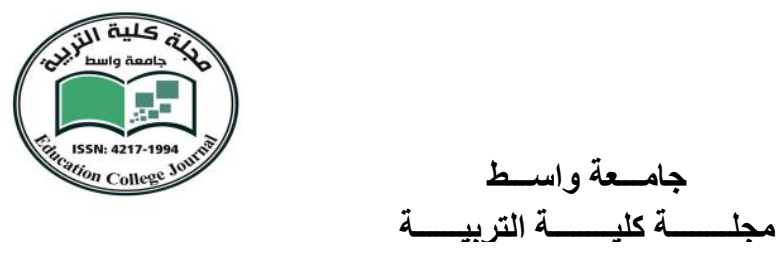

Rhinoceros when he states "it's a kind of sorrow hard to articulate. I feel out of place around others, thus I adore drinking." I feel out of place. Life is for him an irregular business.........more people are dead than they are... .....live becoming uncommon" (Ionesco,1959). His buddy Jean believes in the will of men and tells him to fight with patience, with culture and with the support of the spiritual weapons. However, he even gives up finally. The Theatre of the Absurd does not mean, however, the words "absurd", which denote an incongruity of illogicality. At least several of the different famous ancient plays have looked not only to men from future generation but even to several contemporaries as ill-logical or unrealistic. The indirect remarks on Shakespeare's chronicle plays are a classic example.

The word, the sort of play, according to Holman and Harmon, that represents the absurdity of the human predicament through the abandonment of ordinary or logical equipment and the employment of non-realist forms. The "Theater of the Absurd," the phrase coined by the Hungarian born critic Martin Esslin in his groundbreaking work The Theater of the Absurd (1962), is a specific type of play that first became widespread in the 1950s or 1960s and that shows the philosophical existence enunciated by Albert Camus, French philosopher, in his essay in 1942, The Myth of Sisyphus. Albert Camus claimed that humankind had to renounce the acknowledgement that the world was not totally satisfactory, and in that sense, the entire universe had to be considered eventually as ludicrous. There are many variables to consider when writing a play in this manner. First of all, you need to know that these pieces are written existentially and consequently have no apparent purpose, genuine order or significance. It may still be educational, though, and the audience should be thinking about what is happening in a scene, with the aim of causing thinking through laughing. There are always powerful moments, but it never looks like conventional theater, as it has no beginning, center or conclusion. In addition, a writer has to be conscious that the screenplay cannot observe a predetermined structure and that the dialogus/language is subjugated to a rumbling pastime or game which generally drives the audience into disarray. A sense of geography is scant, and people must navigate in a vacuum-like area. However, the assumption that there is no catharsis or writing is typically immobile. In the end, an 'absurd' playwright 


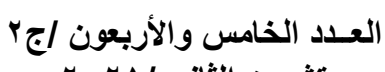

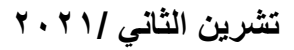

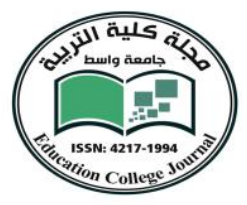

must comprehend that there should be nothing and that it should stop where it began. Moreover, mostly through abstraction of the scenario and by defining what is happening, the audience may relate to this sort of drama. The audience is truly pushed to reflect on the challenges they're facing in the play while seeing the characters trying to sort out a realistic lifestyle. Normally, there are no events telling a tale, but rather visuals presenting humans in an unfathomable universe as perplexed individuals. This is an excellent explanation of the events in Waiting for Godot (1982). Nothing happens. Nothing tends to occur. They sit, while away time and talk nonsensenothing, and wait in vain for Godot, but who never appears. The readers who are attentive and meticulous will laugh uncontrollably as they read the illustration since the setting is not just chaotic, but the bizarre conversations between the two waiters or tramps are also terrific. The Theater of the Absurd is a catch-phrase that has been widely used and abused. It is important to explore its meaning and the justification of its emergence. A considerable number of dramatists categorized on this classification will indignantly reply if they belong to the Theater of the Absurd - and very properly so - that they are not part of such a tendency. Every dramatist concerned tries to communicate his own particular worldview no more and nothing less. Martin Esslin considered the term 'Theater of the Absurd' simply to be an appliance by which he wanted, in the plays of a range of dramatists, to draw attention to certain basic features that could not be perceived as a school but that all appeared to share in a particular attitude to man in the entire predicament of world. The dramatists categorised themselves loosely under the banner of the ridiculous strive to communicate their feelings of confusion, fear and amazement to an unfathomable world. According to Martin Esslin, the movement's five most prominent playwrights are, however, the stalwarts Eugène Ionesco, Samuel Beckett, Jean Genet, Arthur Adamov, Harold Pinter, and Tom Stoppard, and occasionally the words "anti-theaters" or "new theaters" are preferred to have been used. The Absurd Theater was created in France, with key figures including French-born Jean Genet, Russian-born Arthur Adamov, Spanish Mofocco's Fernando Arrabal, Dublin's Samuel Beckett, Romansh's Eugene Ionesco. But such critical notions are important when new ways of expressing art evolve (McMahon, 


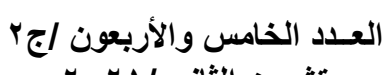

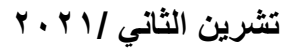

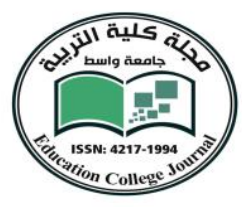

1963). When Eugene Ionesco, Samuel Beckett, Jean Genet and Arthur Adamov came on stage for the first time, most of the critics and spectators were bewildered and enraged. And don't be surprised. Those plays do not comply with all the rules by which the theater has long been evaluated, therefore it must be a provocation for people who walk into the theater and expect to discover what they consider a well-created play. A really well play will have well-observed and persuasively motivated characteristics, frequently with few recognizable human beings and with totally unmotivated movements. The ding-dong of intelligent and rationally constructed speech, which seems to degraded into meaningless babble in some plays, is predicted to play well. It is assumed that a good play will have an exposition, a middle plot and a well-integrated denouement/ending: these plays typically begin in a random way and appear as haphazardly to finish. These plays are not only detestably awful, but do not even merit the word 'drama' according to the established norms of critical appraisal of the theater. The existence of man is ridiculous since we are born without looking to be born and thrust to death without wanting to die, the absurd dramatists feel. We exist in our body and our reason between birth and death, unable of thinking about a time in which we have not been or time in which we have not been. We feel like we are powerful beings, endowed with our senses, volition and reason. In spite of that, our senses/understanding lie to our thinking and our thinking challenges our feelings. We are never really aware of anything. In other words, man is alienated from its existence (Hoefer, 1962). The ridiculous theater rebelled openly against the classical theater. It was "anti-theater," as Eugene Ionesco termed it. It was bizarre, irrational, devoid of conflict and without any specific plot. The discourse appeared often nonsensical in its entirety. And not unexpectedly, it was incomprehension and rejection that the public first responded to this new theater.

In the next section, the study focuses on one of the prominent work of Harold Pinter which is Birthday Party. The play is very important work; its philosophy expresses the resistance toward the current ideology which attempts to impose power on people of the age. And unfortunately, the authority which adopted the ideology has succeeded to subject man. Putting it differently, in the discussion the paper will clarify the status quo of modern 


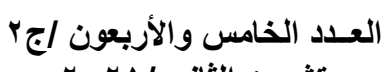

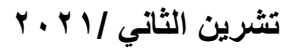

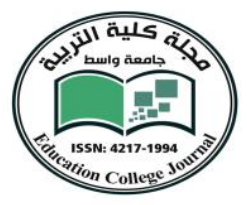

man, specifically after WWII. The analysis of Pinter's Birthday Party is an attempt to describe the tragedy of age at which man is aloof from his past, present and future. There is no value for time, people emotion, intellect. That is manifested via language structure utilized in the text.

\section{Discussion and Findings}

The lack of confidence in language as a medium of communication is one of the most fundamental features of the absurd theater. Language, it appears, has become a medium for traditionalized exchanges of meaningless, stereotyped and interpretations. The following extract shows that character uses language without making sense of what they talking about, they use language to waste time as a tool to evade from reality. Such act sheds light of the tragic condition at which man modern lives.

Meg. Is it good?

Petey. Not bad.

Meg. What does it say?

Petey. Nothing much

Meg. You read me out some nice bits yesterday.

Meg. Will you tell me when you come to something good?

Petey. Yes. (pause) (Pinter, 1965: 10).

Criticism of language closely reflects the theatre, which is a device for rationality and exploration of reality, the concern for contemporary philosophy with language, its effort to detach it from the universe of emotive and illogical uses, grammatical conventions which in the past were often confused with genuine logical relations. In the same way, the Absurd Theater has much in common with the existentialist philosophy of Martin Heidegger, Jean Paul Sartre, and Albert Camus, in emphasizing the underlying absurdity of the human predicament and the bankrupts of closed thinking systems and promises to give an overall explanation of reality. But the Theater of the Absurd may be contemporary.

The substance of human experience cannot be expressed by words that cannot go beyond its veneer. The Theater of the Absurd, in the first place and as an unreliable and insufficient vehicle of communication, was an assault on 


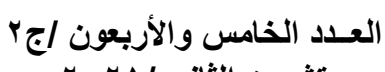

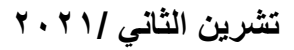

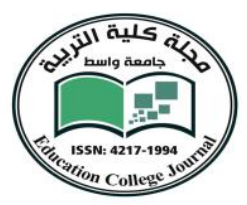

language. However, in traditional sense, language should comply with the basic requirements of the modern man. Moreover, absurd plays employ conventionalized words, clichés, buzzwords and technical jargons that distort, parodize and disintegrate them. As it is shown in the following extract which is between Meg and Stanley. Their conversation lead to no sense. The language they use shows the inner collapse of modern man under the pressure of authority:

Meg. (entering) Well, I bet you don't know what it is?

Stanley. Oh yes I do.

Meg. What

Stanley. Fried bread.

Meg. He knew.

Stanley. What a wonderful surprise.

Meg. You didn't expect that, did you?

Petey. (rising) Well, I'm off.

Meg. You going back to work?

Petey. Yes. (Pinter, 1965: 16).

The Absurd Theater attempts to make people aware of the capacity to transcend common norms of speech and communicate with more authenticity by mocking conventionalized and stereotypic patterns. Therefore, a word such as the absurd theatre has to be regarded as a sort of psychological abstract to create a complicated design of affinities in approach, technique and habit, collected, conscious or unconscious propositions, and influences in the common store of tradition. Therefore, this type of labeling helps to comprehend, just to the extent that it contributes to an intuition into a piece of art. The categorization is not obligatory; it is surely not all encompassing or restrictive. A picture may comprise parts that are best comprehended in view of this stamp, and others in the same picture are derived from a different convention and can be comprehended best.

The action of the absurd plays usually aims at symbolically illustrating the thoughts of the performer and at creating a dramatic temperature to keep the audience interested. Some of their plays look at first 


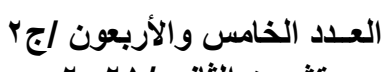

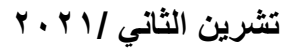

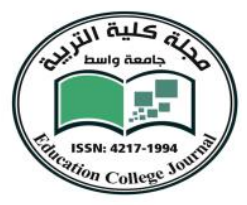

look absolutely nonsensical till we know that the rationality of the mind of author is not communicated explicitly, but metaphorically shown through actions. The delusional people don't fear darkness in art. The Absurd Theatre invades the comfortable certitudes of religious, socio-political orthodoxies. Its objective is to galvanize its readers or audiences out of complacency, to bring forth face to face the sad, harsh realities of life and human condition as these playwrights see it. They applied it for the darkness which they find as a direct representation of real life. There can be no question that such a disappointment and the disintegration of all previously unshakable ideas are trends of our contemporary age. The socio-political and spiritualphilosophical reasons for such meaning are so many and convoluted: the decline of the religious faith which began with the Enlightenment $\left(17^{\text {th }}\right.$ and $18^{\text {th }}$ century) and brought Frederick Nietzsche to articulate of the "death of God" in the 1880s; the collapse of liberal conviction in social development in a result of the World War First; There can be little doubt: the world of the mid-20th century has simply ceased to have significance for many knowledgeable and reasonable folks. Earlier certainties have disappeared, the firmest basis has fallen for hope and optimism. Suddenly man is confronted with an astonishing and illogical cosmos - in short, ludicrous. Every hope, all ultimate meaning explanations were abruptly exposed as foolish delusions, void conversations and whispering in darkness. If we want to envisage this circumstance in the regular life, we may soon disappear understanding the discourse in a crowd of strangers; at one point what made sense became an obscure vocal babble in a foreign tongue in the next. The cozy, familiar scene at once would become one of horror and nightmares. The loss of the optimism drives us towards darkness and uncertain space and time.

We should be forced to perceive this world as a sequence of terrible pictures with the eyes of total stranger. Samuel Beckett is an image breaker and an iconoclast. He has transcended traditions and established a unique type of theater. Pinter's play is characterized as because of the two sinister strangers McCann and Goldberg who have come recently to Stanley's accommodation. They turn the party which supposes to be full of happiness and joy into menace and scary silence. As shown in the following extract: 
the function of drama than now, the following dialogue shows the fact:

Goldenberg. Do you recognize an external force, responsible for you, suffering from you?

Stanley. It's late.

Goldenberg. Late! Late enough! When did you last pray?

McCann. He is sweating! (Pinter, 1965: 40).

McCann and Goldberg represent the outside power which is imposed on modern man to destroy him/her. Stanley escape from nowhere to boardinghouse an in attempt to find a meaning for his life and live in peace without interference of sinister power that control use but he fails to conceal himself from them, they discover his place then at the end of the play they take him with them to nowhere:

Goldenberg. Where did you come from?

Stanley. Somewhere else.

Goldenberg. Why did you come here?

Stanley. My feet hurt!

Goldenberg. Why did you stay?

Stanley. I had headache!

Ros: In where?

Guild: Out her.

Ros: In out here? (Pinter, 1965:48).

Pinter's fame lies in his full-length plays, notwithstanding his work as a poet and film writer. Probably the most well-known are The Birthday Party, The Caretakers, The Homecoming, No Man's Land and Betrayal. In the terms of menace comedies and social comedies it is conventional to speak about Pinter's works. This distinction arose because to what may seem to be a very distinctive breakdown between an early play, like The Birthday Party, and a later, likes the No Man's Land. In the early plays, the readers laugh, but on the other hand a fierce, adverse force threatens to kill one or more of the principal characters. The subsequent plays include less violent effects, more delicate comics, and considerably less darkness. Pinter, who acknowledged that Beckett played a huge role on his writings, highlighted such nonsense as 


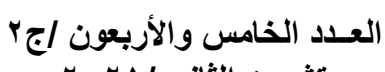

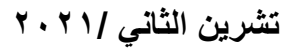

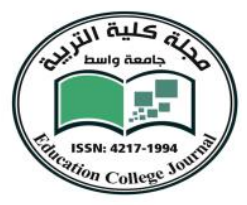

the sensation of rootless condition, alienation and loneliness. Pinter never finds that he needs to explain why in his plays whatever happens or whoever is, there is adequate reason in the drama itself. In general, the absence of explanation marks Pinter's work and the disruption of external influences in a steady manner on the environment. However, Pinter's universe in the drama appears at least to be somewhat realistic, unlike Beckett and Ionesco. Harold Pinter, who has gained the distinction of having a tape recorder built up into a memory with uncanny precision in reproducing a genuine discussion among English people, showed, indeed, that the majority of the conversations every day are mostly unreasonable. At this stage, the Theater of the Absurd can really be the most realistic. For, if the actual discussion of people is ludicrous and unreasonable, then the well-maintained play with its refined logical speech is unreal, but the ludicrous play is perhaps a copy of reality recorded on a band. Or, the Theater of the Absurd is the most naturalistic criticism, the most precise recreation of, reality, in a world that has gone unreal.

\section{Conclusion}

The theater of the Absurd expresses a struggle to embrace and bear the wretched human circumscribed lot. Also, it sheds light on ambiguity, absurdity and irrationality of life, specifically, after WWI and WWII. It is observed that the riddles of existence are not solved simply, because in the end, human beings are alienated in an inconsequential universe and meaningless existence. The Absurd movement expresses the sense of tragedy via focusing on persistent themes of meaninglessness, void lack of understanding, and allusion. Such types of themes are embedded within a type of text characterized as equivocal and evasive. It is observed that the portrait of man is described as unpleasant, full of fraud, lies and menace. On social level, we notice that there is a contrast in social structure; for instance the devaluation in the use of language prove the fact. In other words, absurdist movement does not use or utilize language in traditional sense to communicate their true feelings and emotions but language for them serve a $\mathrm{s}$ a tool to deconstruct the conventions of social standard. Thus, the tragedy of this sort of supplies readers with a vision of how society victimized man and 
العـدد الخامس والأربعون اجن التبري

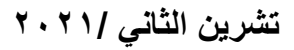
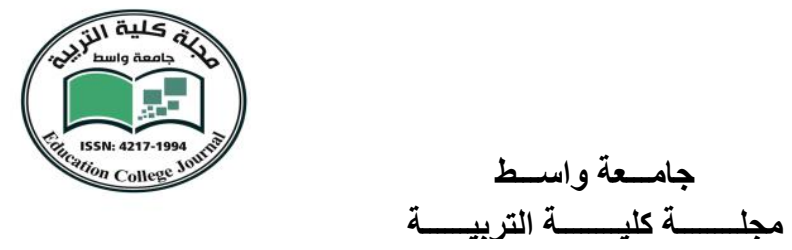

treats people without equity. Such conditions confirm the tragic circumstances within which modern man lives. For further studies, researchers can conduct studies on the collapse of modern man's psyche in any Absurd play. 


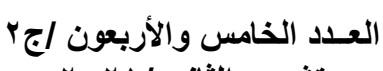

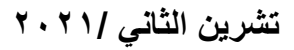

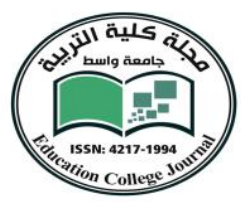

\section{Bibliography}

Ali, H \& Pourgiv, F. 2006. "Harold Pinter: The Absurdist Existentialist Playwright". Journal of Social Sciences and Humanities of Shiraz University. Vol. 23. No. 146. P. 1-10.

Bennett, M. Y. 2011. Reassessing the Theatre of the Absurd: Camus, Beckett, Ionesco, Genet and Pinter. Hampshire: Palgrave Macmillan.

Caselli, D. \& Beckett's D. 1997. "Intertextuality in the Fiction and Criticism". ISBN 0-71907156-9. Cronin, Anthony. Samuel Beckett: The Last Modernist. New York: Da Capo P. 2045.

Gaensbauer, D. B. 1996. Eugène Ionesco Revisited. New York: Twayne.

Hoefer, J. 1962. Pinter and Whiting: Tow Attitude towards the Alienated Artist. Modern Drama. Vol. 4. No. 4. P. 402-408.

Ionesco, E. 1959. Rhinoceros. Paris: Dusseldorf.

Lewis, A. 1972. Ionesco. New York: Twayne.

McMahon, J. H. 1963. The Imagination of Jean Genet. New Haven: Yale UP.

Driver, Tom Faw. 1966. Jean Genet. New York: Columbia UP, Mercier, V. 1977. Beckett/Beckett. Oxford UP, ISBN 0-19-281269-6.

Mohsin, M. \& Sagheer, S. 2019. "The significance of Deictic Expressions in completing meaning of Absurd Theater: The Case of Pinter's Birthday Party". Paideumajournal. Vol. No. P.

Pinter, Harold. 1965. The Birthday Party. London: Croydon. 